九州大学学術情報リポジトリ

Kyushu University Institutional Repository

Expanding the applications of microvascular surgical techniques to digestive surgeries : A technical review

Uch iyama, Hideak i

Department of Surgery and Science, Graduate School of Medical Sciences, Kyushu University

Shirabe, Ken

Morita, Masaru

Kakeji, Yoshihiro

他

http://hdl. hand le. net/2324/27277

出版情報：Surgery Today. 42 (2)，pp.111-120，2012-02-01. Springer

バージョン：

権利関係 : (C) Springer 2011 


\title{
Expanding the applications of microvascular surgical techniques to digestive surgeries: a technical review
}

\author{
Hideaki Uchiyama, Ken Shirabe, Masaru Morita, Yoshihiro Kakeji, Akinobu \\ Taketomi, Yuji Soejima, Tomoharu Yoshizumi, Toru Ikegami, Noboru Harada, \\ Hiroto Kayashima, Kazutoyo Morita, Yoshihiko Maehara \\ Department of Surgery and Science, Graduate School of Medical Sciences, \\ Kyushu University, Fukuoka 812-8582, Japan
}

Address for correspondence, and to whom reprint requests should be addressed: Hideaki Uchiyama,

Department of Surgery and Science, Graduate School of Medical Sciences, Kyushu University, Fukuoka 812-8582, Japan

Fax:+81-92-642-5482Ｅ-mail: huchi@surg2.med.kyushu-u.ac.jp

Short title: Microvascular surgery in digestive surgery

Article type: Review article

Key words: microvascular surgery, digestive surgery, vascular reconstruction 


\section{ABBREVIATIONS}

HA, hepatic artery; HAD, hepatic artery dissection; HAT, hepatic artery thrombosis; LDLT, living donor liver transplantation 


\section{ABSTRACT}

In living donor liver transplantation (LDLT), it is considered safer to reconstruct hepatic arteries (HAs) under a microscope than under conventional loupe magnification because graft HA stumps are generally thin and short with an average diameter of approximately $2 \mathrm{~mm}$. We first applied microvascular surgical techniques to HA reconstruction in LDLT in 1996. In most cases, we use a disposable double-clip to secure the graft and recipient arteries, and interrupted 8-0 non-absorbable monofilament sutures. We next started performing resection and reconstruction of the right HA in a surgery for hilar cholangioma using the same technique as in LDLT. Lately, we have started applying microvascular surgical techniques to various digestive surgeries; namely, supercharge and superdrainage in esophageal surgery, vascular reconstruction in free jejunal interposition grafts for cervical esophageal cancer, resection and reconstruction of spontaneous HA aneurysms, jejunal artery reconstruction for spontaneous superior mesenteric artery dissection, and so on. Mastering this technique is time-consuming. However, once a surgeon masters this technique, it has almost unlimited applications and most vital vessels can be safely reconstructed using this technique. We herein provide a technical review of the application of microvascular surgical techniques for various digestive surgeries. 


\section{Introduction}

With the advances in microvascular surgical techniques, various free tissue transfers have been successfully accomplished in the last two decades in the field of plastic surgery. ${ }^{1-5}$ In digestive surgery, especially gastrointestinal and hepato-biliary-pancreatic surgery, surgeons occasionally encounter situations where tiny blood vessels must be reconstructed. We introduced the microvascular surgical technique for hepatic artery (HA) reconstructions in living donor liver transplantation (LDLT) in $1996 .{ }^{6}$ Since then, we have applied this technique to various digestive surgeries. We herein review the various microvascular surgical techniques and the expanding applications of these techniques for gastrointestinal and hepatobiliary-pancreatic surgeries.

\section{Microvascular surgical technique for artery reconstructions}

During both regular and microvascular artery reconstruction, direct end-to-end anastomosis is the most desirable mode of reconstruction, because straight and direct arterial flows from an inflow artery can effectively prevent thrombosis formation. In our experience, we have not used any end-to-side anastomosis for artery reconstructions using the microvascular technique. The schematic diagrams of our procedures are shown in Fig. $1 .^{6}$ In almost all cases, we have been able to reconstruct arteries in this manner using a double-clip. The use of double-clips enables us to safely reconstruct tiny arteries, preventing excessive tension at an anastomosis. Approximately $45-60 \mathrm{~g}$ grasp force of a double-clip is appropriate. Only when it is not possible to use a double-clip, for example, when reconstructing a short stump artery or a very hard artery to be grasped by 
a double-clip, do we reconstruct arteries using only traction sutures on both sides of angle stitches. Although some surgeons have reported the usefulness of double-armed stitches for artery reconstructions, ${ }^{8}$ a single-armed stitch with an approximately $3 \mathrm{~cm}$-long string will suffice in most cases. We have used 8-0 or 9-0 Prolene ${ }^{\mathrm{TM}}$ according to the diameter of the artery to be reconstructed. We do not use antiplatelet agents nor anticoagulants to prevent vascular thrombosis after microvascular reconstructions.

\section{Microvascular surgical technique for vein reconstructions}

Because veins have a more flexible wall compared to arteries, it is easy to manipulate the wall during vein reconstruction. However, vein flows are generally slower than arterial flows, and it is thought that reconstructed veins have a greater tendency to form blood clots, which eventually leads to thrombosis formation at the anastomosis, compared to reconstructed arteries. To prevent this complication, we extrovert vein walls using vertical mattress sutures so that the inner layers of each vein are attached to each other (Fig. 2). In most cases, veins are also reconstructed by direct end-to-end anastomosis. During vein reconstructions in free jejunal graft interposition, however, an inflow vein (one of the jejunal veins) can be directly anastomosed to a large drainage vein (the internal jugular vein) in an end-to-side manner (Fig. 3). Generally, although interrupted sutures are preferred in microvascular reconstructions, continuous sutures should be applied for an end-to-side anastomosis because the veins are no longer turned over in this mode of reconstruction. ${ }^{9}$ 


\section{Hepatic artery reconstruction in living donor liver transplantation (Fig. 4)}

Reconstructing the HA is still one of the most difficult procedures in LDLT. HA complications such as HA thrombosis (HAT) or HA dissection (HAD) often lead to serious morbidity and mortality of liver transplant recipients. ${ }^{10,11}$ In contrast to cadaveric liver transplantation, LDLT graft HAs to be reconstructed usually have a thinner diameter and a shorter stump. It is generally considered safer to reconstruct HAs under a microscope in LDLT. ${ }^{12}$ As of October of 2010, we had performed 373 cases of LDLT, in which almost all HA reconstructions were performed under a microscope using the microvascular surgical technique. This technique was first reported in 1992 by Mori et al. ${ }^{13}$ We introduced this technique for HA reconstruction in LDLT in $1996 .{ }^{6}$ The procedure is schematically shown in Fig 1. So far, we have experienced only 6 HA complications in a total of 373 cases of LDLT (1.6\%) (Table 1). With cumulative experience in HA reconstruction under a microscope, the incidence of HA complications has gradually decreased. Most of these HA complications occurred in our early experience. With regard to the management of HA complications, our first choice is surgical revision of the HA anastomosis, although there have been some reports regarding non-surgical interventional therapy or retransplantation. ${ }^{14-16}$ In the 6 cases of HA complications, we accomplished successful revision in 4 cases. In one case of HA thrombosis, revision of the HA anastomosis was impossible, and the patient needed a retransplantation. In the other case of HA thrombosis, the recipient died of multiple organ failure irrespective of HA re-reconstruction. 
Hepatic grafts in LDLT often have two or more HA stumps. In our experience, $92(26 \%)$ hepatic grafts had 2 HA stumps and 4 (1\%) had 3 HA stumps. There has been a controversy about whether all HA stumps should be reconstructed. The liver has fine intrahepatic arterial networks ${ }^{17}$ so that reconstructing only 1 HA might maintain the minimum arterial supply for a hepatic graft to survive. ${ }^{18,19}$ However, we believe that a hepatic graft would be in a condition of relative arterial ischemia if the HAs on the graft were incompletely reconstructed. ${ }^{20}$ We observed a high incidence of anastomotic biliary stricture in LDLT recipients who underwent incomplete HA reconstruction..$^{21,22}$ Graft HAs are usually reconstructed using the recipient HA branches, namely, the left, the middle, or the right HAs. Selection of these arteries is very important, especially when biliary reconstruction is done by a duct-to-duct anastomosis. When considering the use of the recipient right HA for hepatic artery reconstructions, the right HA has to be dissected free from the common hepatic duct. This results in the interruption of the small nourishing arteries into the common hepatic duct from the right HA, which can lead to anastomotic biliary stricture. We prefer to use the recipient left HA for HA reconstruction in LDLT to avoid this complication. ${ }^{23}$

When the recipient HA branches can no longer be used for HA reconstructions because of fragile arterial walls or hardened arteries caused by reoperation or preoperative transarterial embolization for hepatocellular carcinoma, recipient arteries other than HA branches have to be used. We have named this mode of HA reconstruction "extra-anatomical HA reconstruction". ${ }^{24}$ We have used the right gastroepiploic arteries, the left gastric arteries, the splenic arteries, and so 
on. The long-term outcomes of our LDLT patients with extra-anatomical HA reconstruction were comparable with those of patients who underwent conventional anatomical HA reconstructions. ${ }^{24}$

We have so far used a total of three interposition grafts for HA reconstructions in LDLT (one splenic artery, one superior rectal artery, and one right gastric vein graft). Although some surgeons have reported the utility of interposition vein grafts for HA reconstruction, ${ }^{25,26}$ we think that a vein graft should be used as a last resort, because we experienced a case where an aneurysm formed at the interposition vein graft. ${ }^{27}$

\section{Supercharge and superdrainage of a right hemicolon conduit for an esophageal substitute (Fig. 5)}

In our department, the first choice of an esophageal substitute is the stomach tube. ${ }^{28}$ When the stomach tube is no longer available, for example after a gastrectomy or due to simultaneous gastric lesions, we use a right hemicolon conduit for an esophageal substitute after subtotal esophagectomy for esophageal cancer. We prefer to bring up a right hemicolon conduit to the neck through a subcutaneous route in order to avoid serious consequences in case of anastomotic leakage or conduit necrosis..$^{29,30}$ The bought-up right hemicolon tends to be congestive because of the long-route drainage vein (usually the middle colic vein), which may disturb microcirculation of the conduit and result in anastomotic leakage. ${ }^{31}$ To avoid this complication, we create a new venous drainage route, called superdrainage. Usually, the ileocolic vein is anastomosed to one of the cervical veins to let the congested blood drain. The 
selection criteria by which the cervical veins are selected is that a good drainage vein has blood-stream flow that reflects the heart pumping. The internal jugular vein is the preferred vein in the neck. Other candidate drainage veins are the anterior cervical vein, the external jugular vein, and so on. Because a direct anastomosis of the ileocolic vein to the internal jugular vein cannot be accomplished in most cases, we have recently used an inferior mesenteric vein graft interposition to fill the gap between the two vessels. ${ }^{32}$ After the congested blood is cleared by superdrainage, the color of the brought-up hemicolon is usually restored, and the pulsation of the ileocolic arterial stump becomes strong enough so that the ileocolic artery reconstruction (supercharge) is no longer needed. Only when the pulsation of the ileocolic arterial stump is weak, do we reconstruct the ileocolic artery using the cervical transverse artery, the inferior thyroid artery, etc. We have so far reconstructed only 3 ileocolic arteries. Using the abovementioned strategies, we have not encountered any cases of conduit necrosis, the most serious complication of this mode of esophageal reconstruction.

\section{Free jejunal graft interposition for cervical esophageal cancer (Fig. 6)}

Free jejunal graft interposition was first reported by Seidenberg et al. in 1959. ${ }^{34}$ Since then, the procedure has become popular with the advent of microvascular surgical techniques. ${ }^{35,36}$ Most vascular reconstructions using this procedure are done by plastic surgeons in the Department of Otolaryngology in our hospital. When free jejunal interpositions were unexpectedly needed during esophageal surgery, we reconstructed the jejunal vessels under a microscope ourselves. We 
have so far reconstructed jejunal arteries and veins in four cases of free jejunal graft interposition without any vascular complications.

\section{Hepatic artery reconstruction in hilar cholangiocarcinoma surgery}

Sometimes, it is necessary to resect and reconstruct the HAs during hilar cholangiocarcinoma surgery because of direct invasion. ${ }^{37,38}$ It is generally considered that combined HA resection does not confer any apparent survival benefit when the hilar cholangiocarcinoma directly invades into the HA. So far, we have experienced two HA reconstructions while resecting hilar cholangiocarcinomas. In one case, an extended left hepatectomy combined with a right HA reconstruction using the gastroduodenal artery was performed (Fig. 7). In the other, an extrahepatic bile duct resection combined with a left HA reconstruction was performed.

\section{Hepatic artery reconstruction in resecting hepatic artery aneurysms (Fig.}

\section{8)}

Spontaneous HA aneurysms are very rare, and are generally not diagnosed before they become symptomatic. We encountered an elderly female with spontaneous HA aneurysms which were incidentally found on screening ultrasound. Because the risk of rupture of HA aneurysms is high, ${ }^{39-41}$ we resected the aneurysms and reconstructed the HA proper. Although some surgeons have reported aneurysm ligation and excision without revascularization in case reports,${ }^{40,41}$ we believe that revascularization should be performed if it is technically feasible, because arterial ischemia leads to 
intrahepatic bile duct ischemia which can result in abscess formation or refractory cholangitis.

\section{Right gastroepiploic artery reconstruction in subtotal pancreatectomy for}

\section{a huge intrapapillary mucinous carcinoma (Fig. 9)}

We encountered a case of huge intrapapillary mucinous carcinoma of the pancreas. The tumor had invaded the left gastric artery, and complete resection of the dorsal pancreas combined with splenectomy was necessary. To resect the huge tumor, it was necessary to divide the four main gastric arteries; namely, the left gastric, the right gastric, the left gastroepiploic, and the right gastroepiploic arteries. After resection of the tumor, the color of the stomach was poor and we were forced to decide whether to perform a total gastrectomy. The stump of the anterior inferior pancreaticoduodenal artery was dissected free from the surrounding tissue and anastomosed to the right gastroepiploic artery, whereby the color of the stomach was restored via the extensive vascular collaterals in its wall. ${ }^{42}$

\section{Jejunal artery reconstruction in spontaneous superior mesenteric artery}

\section{dissection (Fig. 10)}

We encountered a middle-aged male with a diagnosis of spontaneous superior mesenteric artery dissection. His symptom was severe postprandial abdominal angina resembling acute abdomen. CT angiography revealed a spontaneous superior mesenteric artery dissection which extended to the peripheral branches. Although some papers reported successful conservative therapies, ${ }^{43-45}$ 
we performed the operation with a strong suspicion of ischemic necrosis of the intestine. The dissection wall extended to the jejunal and ileal arterial branches, the middle colic artery, and the ileocolic artery. The marginal arteries were intact. The color of the entire jejunum was dark, and impending ischemic necrosis of the jejunum was strongly suspected. It was impossible to reconstruct all branches of the superior mesenteric artery ${ }^{46,47}$ or place a stent. ${ }^{48-51} \mathrm{We}$ dissected the right gastroepiploic artery free from the greater curvature, which was anastomosed to the $4^{\text {th }}$ jejunal artery, whereby pulsatile arterial blood spread over the entire small intestine via the marginal arteries. The patient recovered well and has since been completely free of postprandial angina.

\section{Conclusions}

We have described our microvascular surgical techniques and our experiences with microvascular surgeries in the field of gastrointestinal and hepatobiliary pancreatic surgery. The first author (H.U.) has personally experienced the various microvascular surgeries which are enumerated in Table 2. In our Department, there is approximately one case of LDLT every week and at least one case of esophageal surgery every month which requires microvascular surgical technique. Therefore, there are approximately 60 microvascular surgeries performed every year at our institution. Microvascular surgery is generally done by a plastic surgeon. However, this number of microvascular surgeries is so large that it is not possible to obtain the assistance of a plastic surgeon every time. In addition, it is very difficult to adjust the time schedules between general surgeons and plastic surgeons. The availability of a few 
general surgeons who have mastered microvascular surgical techniques in a Department of General Surgery is very helpful. We have three general surgeons (including the first author) who can reconstruct blood vessels using these techniques in our department. We will continue to pass on these techniques to several young surgeons, letting them attend as many microvascular surgeries as possible. Although mastering this technique is time-consuming, once a surgeon masters it, its applications are almost unlimited, and most vital vessels can be successfully reconstructed. 
Table 1. Hepatic artery complications in a total of 373 cases of living donor liver transplantation.

\begin{tabular}{|c|c|c|c|}
\hline Complication & $\begin{array}{l}\text { Clinical } \\
\text { presentation }\end{array}$ & Treatment & Outcome \\
\hline HA aneurysm & $\begin{array}{l}\text { Incidental finding } \\
\text { on a follow-up CT }\end{array}$ & $\begin{array}{l}\text { Aneurysm } \\
\text { resection and } \\
\text { re-anastomosis at } \\
4 \text { years after } \\
\text { LDLT }\end{array}$ & Alive, 11 years \\
\hline HAT & $\begin{array}{l}\text { Elevated } \\
\text { transaminases }\end{array}$ & $\begin{array}{l}\text { ReLDLT at } 47 \\
\text { days after the } \\
\text { primary LDLT }\end{array}$ & Alive, 11 years \\
\hline HAT & $\begin{array}{l}\text { Elevated } \\
\text { transaminases }\end{array}$ & $\begin{array}{l}\text { Re-anastomosis at } \\
7 \text { days after the } \\
\text { LDLT }\end{array}$ & Died, 10 days \\
\hline HAD & $\begin{array}{l}\text { Dullness of HA } \\
\text { pulses on Doppler } \\
\text { ultrasonography }\end{array}$ & $\begin{array}{l}\text { Re-anastomosis at } \\
7 \text { days after the } \\
\text { LDLT }\end{array}$ & Alive, 8 years \\
\hline HAD & $\begin{array}{l}\text { Dullness of HA } \\
\text { pulses on Doppler } \\
\text { ultrasonography }\end{array}$ & $\begin{array}{l}\text { Re-anastomosis at } \\
10 \text { days after the } \\
\text { LDLT }\end{array}$ & Alive, 4 years \\
\hline $\begin{array}{l}\text { HA } \\
\text { pseudoaneurysm }\end{array}$ & $\begin{array}{l}\text { Incidental finding } \\
\text { on a follow-up CT }\end{array}$ & $\begin{array}{l}\text { Aneurysm } \\
\text { resection and } \\
\text { re-anastomosis at }\end{array}$ & Alive, 2 years \\
\hline
\end{tabular}


4 years after

LDLT

HA, hepatic artery; HAD, hepatic artery dissection; HAT, hepatic artery thrombosis; LDLT, living donor liver transplantation 
Table 2. Personal experiences with the application of microvascular surgery to digestive surgeries (between October 1996 and October 2010).

$\begin{array}{ll}\text { Surgical procedure } & \text { N }\end{array}$

Living donor liver transplantation

Hepatic artery reconstruction

Esophageal cancer surgery

Superdrainage

Supercharge

3

Free jejunal graft interposition

Bile duct cancer surgery

Hepatic artery reconstruction

Gastric cancer surgery

Hepatic artery reconstruction

Hepatic artery aneurysm

Hepatic artery reconstruction

Pancreatic cancer resection

Right gastroepiploic artery reconstruction

Superior mesenteric artery dissection

Jejunal artery reconstruction 1

Total 401 
The authors have no conflict of interest with regard to the content of this manuscript.

\section{References}

1. Petrie NC, Chan JK, Chave H, McGuiness CN. The inferior mesenteric vessels as recipients when performing free tissue transfer for pelvic defects following abdomino-perineal resection. A novel technique and review of intra-peritoneal recipient vessel options for microvascular transfer. J Plast Reconstr Aesthet Surg 2010; 63: 2133-40.

2. Cusano A, Fernandes R. Technology in microvascular surgery. Oral Maxillofac Surg Clin North Am 2010; 22: 73-90.

3. Saito A, Sawaizumi M, Imai T, Matsumoto S. Continuous local intraarterial infusion of anticoagulants for microvascular free tissue transfer in primary reconstruction of the lower limb following resection of sarcoma. Microsurgery 2010; 30: 376-9.

4. Chernichenko N, Ross DA, Shin J, Sasaki CT, Ariyan S. End-to-side venous anastomosis with an anastomotic coupling device for microvascular free-tissue transfer in head and neck reconstruction. Laryngoscope 2008; 118 : 2146-50.

5. Ross DA, Chow JY, Shin J, Restifo R, Joe JK, Sasaki CT, et al. Arterial coupling for microvascular free tissue transfer in head and neck reconstruction. Arch Otolaryngol Head Nech Surg 2005; 131: 891-5.

6. Uchiyama H, Hashimoto K, Hiroshige S, Harada N, Soejima Y, Nishizaki T, et al. Hepatic artery reconstruction in living-donor liver transplantation: a review of its techniques and complications. Surgery 2002; 131: S200-4. 
7. Harashina T. Use of the untied suture in microvascular anastomoses. Plast Reconstr Surg 1976; 58: 608-9.

8. Miyagi S, Enomoto Y, Sekiguchi S, Kawagishi N, Sato A, Fujimori K, et al. Microsurgical back wall support suture technique with double needle sutures on hepatic artery reconstruction in living donor liver transplantation. Transplant Proc 2008; 40: 2521-2.

9. Harashina T. Use of a continuous suture for back wall repair of end-to-end or end-to-side anastomoses. Plast Reconstr Surg 1982; 69: 139-44.

10. Settmacher U, Stange B, Haase R, Heise M, Steinmüller T, Bechstein WO, et al. Arterial complications after liver transplantation. Transpl Int 2000; 13: $372-8$.

11. Yanaga K, Lebeau G, Marsh JW, Gordon RD, Makowka L, Tzakis AG, et al. Hepatic artery reconstruction for hepatic artery thrombosis after orthotopic liver transplantation. Arch Surg 1990; 125: 628-31.

12. Inomoto T, Nishizawa F, Sasaki H, Terajima H, Shirakata Y, Miyamoto S, et al. Experiences of 120 microsurgical reconstructions of hepatic artery in living related liver transplantation. Surgery 1996; 119: 20-6.

13. Mori K, Nagata I, Yamagata S, Sasaki H, Nishizawa F, Takada Y, et al. The introduction of microvascular surgery to hepatic artery reconstruction in living-donor liver transplantation - its surgical advantages compared with conventional procedures. Transplantation 1992; 54: 263-8.

14. Kodama Y, Sakuhara Y, Abo D, Shimamura T, Furukawa H, Todo S, et al. Percutaneous transluminal angioplasty for hepatic artery stenosis after living donor liver transplantation. Liver Transpl 2006; 12: 465-9. 
15. Maleux G, Pirenne J, Aerts R, Nevens F. Hepatic artery pseudoaneurysm after liver transplantation: definitive treatment with a stent-graft after failed coil embolisation. Br J Radiol 2005; 78: 453-6.

16. Fistouris J, Herlenius G, Bäckman L, Olausson M, Rizell M, Mjörnstedt L, et al. Pseudoaneurysm of the hepatic artery following liver transplantation. Transplant Proc 2006; 38: 2679-82.

17. Plengvanit U, Chearanai O, Sindhvananda K, Dambrongsak D, Tuchinda S, Viranuvatti V. Collateral arterial blood supply of the liver after hepatic artery ligation, angiographic study of twenty patients. Ann Surg 1972; 175: 105-10.

18. Ikegami T, Kawasaki S, Matsunami H, Hashikura Y, Nakazawa Y, Miyagawa $S$, et al. Should all hepatic arterial branches be reconstructed in living-related liver transplantation? Surgery 1996; 119: 431-6.

19. Kubota K, Makuuchi M, Takayama T, Harihara Y, Hasegawa K, Aoki T, et al. Simple test on the back table for justifying single hepatic-arterial reconstruction in living related liver transplantation. Transplantation 2000; 70: 696-7.

20. Yanaga K, Tzakis AG, Starzl TE. Partial dearterialization of the liver allograft. Transpl Int 1990; 3: 185-8.

21. Uchiyama H, Harada N, Sanefuji K, Kayashima H, Taketomi A, Soejima Y, et al. Dual hepatic artery reconstruction in living donor liver transplantation using a hepatic graft with 2 hepatic arterial stumps. Surgery 2010; 147: 878-86.

22. Suehiro T, Ninomiya M, Shiotani S, Hiroshige S, Harada N, Minagawa R, et 
al. Hepatic artery reconstruction and biliary stricture formation after living donor adult liver transplantation using the left lobe. Liver Transpl 2002; 8: 495-9.

23. Uchiyama H, Ikegami T, Soejima Y, Ninomiya M, Kayashima H, Taketomi A, et al. Use of recipient's left hepatic artery for artery reconstruction in right lobe living donor liver transplantation with duct-to-duct anastomosis. Transplantation 2010; 89: 1016-21.

24. Uchiyama H, Shirabe K, Taketomi A, Soejima Y, Ninomiya M, Kayashima H, et al. Extra-anatomical hepatic artery reconstruction in living donor liver transplantation: can this procedure save hepatic grafts? Liver Transpl 2010; 16: 1054-61.

25. Yang Y, Yan LN, Zhao JC, Ma YK, Huang B, Li B, et al. Microsurgical reconstruction of hepatic artery in A-A LDLT: 124 consecutive cases without HAT. World J Gastroenterol 2010; 16: 2682-8.

26. Margreiter C, Aigner F, Orozco H, Wechselberger G, Ollinger R, Bösmüller C, et al. Hepatic artery reconstruction with inferior mesenteric vein graft in pediatric living donor liver transplantation. Pediatr Transplant 2008; 12: 324-8.

27. Uchiyama H, Soejima Y, Taketomi A, Yoshizumi T, Harada N, Ijichi H, et al. Hepatic artery aneurysm arising from an interposition vein graft four years after auxiliary partial orthotopic liver transplantation. Transpl Int 2007; 20: 197-200.

28. Morita M, Yoshida R, Ikeda K, Egashira A, Oki E, Sadanaga N, et al. Advances in esophageal cancer surgery in Japan: an analysis of 1000 
consecutive patients treated at a single institute. Surgery 2008; 143: 499-508.

29. Cerfolio RJ, Allen MS, Deschamps C, Trastek VF, Pairolero PC. Esophageal replacement by colon interposition. Ann Thorac Surg 1995; 59: 1382-4.

30. Davis PA, Law S, Wong J. Colonic interposition after esophagectomy for cancer. Arch Surg 2003; 138: 303-8.

31. Kono K, Sugai H, Omata H, Fujii H. Transient bloodletting of the short gastric vein in the reconstructed gastric tube improves gastric microcirculation during esophagectomy. World J Surg 2007; 31: 780-4.

32. Uchiyama H, Morita M, Toh Y, Saeki H, Kakeji Y, Matsuura H, et al. Superdrainage of the ileocolic vein to the internal jugular vein interposed by an inferior mesenteric vein graft in replacing the esophagus with the right hemicolon. Surg Today 2010; 40: 578-82.

33. Bradford CR, Esclamado RM, Carroll WR. Monitoring of revascularized jejunal autografts. Arch Otolaryngol Head Neck Surg 1992; 118: 1042-4.

34. Seidenberg B, Rosenak SS, Hurwitt ES, Som ML. Immediate reconstruction of the cervical esophagus by a revascularized isolated jejunal segment. Ann Surg 1959; 149: 162-71.

35. Sarukawa S, Asato H, Okazaki M, Nakatsuka T, Takushima A, Harii K. Clinical evaluation and morbidity of 201 free jejunal transfers for oesophagopharyngeal reconstruction during the 20 years 1984-2003. Scand J Plast Reconstr Surg Hand Surg 2006; 40: 148-52.

36. Shirakawa Y, Naomoto Y, Noma K, Ono R, Nobuhisa T, Kobayashi M, et al. Free jejunal graft for hypopharyngeal and esophageal reconstruction. Langenbecks Arch Surg 2004; 389: 387-90. 
37. Hemming AW, Reed AI, Fujita S, Foley DP, Howard RJ. Surgical management of hilar cholangiocarcinoma. Ann Surg 2005; 241: 693-9.

38. Miyazaki M, Kato A, Ito H, Kimura F, Shimizu H, Ohtsuka M, et al. Combined vascular resection in operative resection for hilar cholangiocarcinoma: does it work or not? Surgery 2007; 141: 581-8.

39. Nyui S, Inoue S, Sato T, Nakase A. Surgical treatment of a huge hepatic artery aneurysm - a case report. Jpn J Surg 1991; 21: 344-7.

40. Schroeyers P, Lismonde M, Vermonden J, Six C. Management of hepatic artery aneurysm. Case report and literature review. Acta Chir Belg 1995; 95: 89-91.

41. Countryman D, Norwood S, Register D, Torma M, Andrassy R. Hepatic artery aneurysm. Report of an unusual case and review of the literature. Am Surg 1983; 49: 51-4.

42. Akiyama H, Miyazono H, Tsurumaru M, Hashimoto C, Kawamura T. Use of the stomach as an esophageal substitute. Ann Surg 1978; 188: 606-10.

43. Nagai T, Torishima R, Uchida A, Nakashima H, Takahashi K, Okawara H, et al. Spontaneous dissection of the superior mesenteric artery in four cases treated with anticoagulation therapy. Intern Med 2004; 43: 473-8.

44. Takayama H, Takeda S, Saitoh SK, Hayashi H, TakanoT, Tanaka K. Spontaneous isolated dissection of the superior mesenteric artery. Intern Med 2002; 41: 713-6.

45. Lamprecht G, Trabold T, Gregor M, Lamberts R. Spontaneous, self-limited, non-atherosclerotic dissection of the superior mesenteric artery. Eur J Gastroenterol Hepatol 2003; 15: 437-9. 
46. Oda T, Ono H, Muranaka H, Takai F. The right gastroepiploic artery as an alternative inflow source in acute mesenteric ischemia. J Vasc Surg 2005; 41: 1061-4.

47. Picquet J, Abilez O, Pénard J, Jousset Y, Rousselet MC, Enon B. Superficial femoral artery transposition repair for isolated superior mesenteric artery dissection. J Vasc Surg 2005; 42: 788-91.

48. Casella IB, Bosch MA, Sousa WO Jr. Isolated spontaneous dissection of the superior mesenteric artery treated by percutaneous stent placement: case report. J Vasc Surg 2008; 47: 197-200.

49. Miyamoto N, Sakurai Y, Hirokami M, Takahashi K, Nishimori H, Tsuji K, et al. Endovascular stent placement for isolated spontaneous dissection of the superior mesenteric artery: report of a case. Radiat Med 2005; 23: 520-4.

50. Yoon YW, Choi D, Cho SY, Lee DY. Successful treatment of isolated spontaneous superior mesenteric artery dissection with stent placement. Cardiovasc Intervent Radiol 2003; 26: 475-8.

51. Leung DA, Schneider E, Kubik-Huch R, Marincek B, Pfammatter T. Acute mesenteric ischemia caused by spontaneous isolated dissection of the superior mesenteric artery: treatment by percutaneous stent placement. Eur Radiol 2000; 10: 1916-9. 


\section{Figure legends}

Fig. 1. Schematic diagram of the microvascular surgical technique for artery reconstruction. (A) After removal of unnecessary connective tissue surrounding the arteries, both an inflow and an outflow artery are secured by a double-clip. Angle stitches (8-0 or 9-0 non-absorbable sutures) are placed on both edges of the arteries. (B) After the clips are moved inward so that both arteries are attached to each other, the angle stitches are tied. (C) Several stitches are placed between the angle stitches. The number of stitches is determined according to the diameter of arteries. These stitches are left untied until all stitches are placed, because it is easier to place each stitch correctly before they are tied (untied suture technique ${ }^{7}$ ). (D) These stitches are tied one-by-one. Then, the double-clip are turned over. (E, F) Several stitches are placed on the other side of the arteries in the same manner.

Fig. 2. Schematic diagram of the microvascular surgical technique for end-to-end vein reconstruction. (A) Angle stitches are placed on the 6 o'clock and the $12 \mathrm{o}^{\prime}$ clock positions. These stitches are placed by means of vertical mattress sutures so that the inner layers of vein walls are attached to each other. (B) After the angle stitches are tied, these stitches are pulled in opposite directions so that the vein walls between the angle stitches are horizontal with appropriate tension. (C) Several stitches are placed between the angle stitches. The number of stitches is determined according to the diameter of the veins. (D) The anastomosing veins are turned over by pulling each angle stitch in the opposite direction. (E, F) Several stitches are placed on the other side of the 
veins in the same manner.

Fig. 3. Schematic diagram of the microvascular surgical technique for end-to-side vein reconstruction. (A, B) Angle stitches are placed at the 3 o'clock and the 9 o'clock positions. These stitches are placed by means of vertical mattress sutures so that the inner layers of veins are attached to each other. (C) After the angle stitches are tied, a continuous suture is placed on the back wall intraluminally. (D) Once the continuous sutures reach the other angle suture, the suture partially returns toward the starting angle suture, suturing the anterior wall. (E) After several upward continuous stitches are placed on the anterior wall, these stitches are discontinued, then, the remainder stitch is used to make downward continuous stitches. (F) When the two continuous stitches meet and are tied, the end-to-side anastomosis is completed.

Fig. 4. Schematic diagram of hepatic artery reconstruction in living donor liver transplantation. Graft hepatic arteries are usually reconstructed using the recipient hepatic arterial branches, namely, the left, the middle, or the right hepatic artery.

Fig. 5. Schematic diagram of supercharge and superdrainage of the ileocolic vessels during replacement of the esophagus with the right hemicolon. First, the ileocolic vein is reconstructed to avoid blood congestion of the brought-up right hemicolon. Only when the pulsation of the ileocolic artery is weak even after the reconstruction of the ileocolic vein, do we reconstruct the ileocolic artery. 
Fig. 6. Schematic diagram of jejunal vessel reconstruction in free jejunal graft interposition. A free jejunal graft, usually a part of the jejunum nourished by the $4^{\text {th }}$ jejunal artery, is harvested. After completion of the intestinal reconstruction, the vascular anastomoses are performed. In most cases, the $4^{\text {th }}$ jejunal vein is anastomosed to the internal jugular vein in an end-to-side manner (Fig. 3). The $4^{\text {th }}$ jejunal artery is anastomosed to the superior thyroid artery. A small portion of the harvested jejunum, sharing the same blood supply as the jejunal interposition, is separated and used as an external monitor for about 3-4 days. ${ }^{33}$

Fig. 7. Schematic diagram of the right hepatic artery reconstruction in hilar cholangiocarcinoma surgery. An extended left hepatectomy combined with a right hepatic artery reconstruction was performed. After resection of a part of the right hepatic artery, it was reconstructed using the gastroduodenal artery.

Fig. 8. Schematic diagram of a hepatic artery reconstruction after resecting hepatic artery aneurysms. There were three aneurysms in the hepatoduodenal ligament; one $9 \mathrm{~mm}$ in diameter in the left hepatic artery, one $11 \mathrm{~mm}$ in diameter in the proper hepatic artery, and one $35 \mathrm{~mm}$ in diameter in the gastroduodenal artery. All aneurysms were resected and the hepatic artery reconstruction was performed in a direct end-to-end anastomosis. The left hepatic artery reconstruction was abandoned because the distal stump of the left hepatic artery was no longer available after resecting the aneurysms. 
Fig. 9. Schematic diagram of the right gastroepiploic artery reconstruction using the anterior inferior pancreaticoduodenal artery. The stump of the anterior inferior pancreaticoduodenal artery was dissecting from the surrounding tissue and anastomosed to the right gastroepiploic artery.

Fig. 10. Schematic diagram of the $4^{\text {th }}$ jejunal artery reconstruction in a case of spontaneous superior mesenteric artery dissection. The right gastroepiploic artery was dissected free from the greater curvature and anastomosed to the $4^{\text {th }}$ jejunal artery. 
Figure 1

A

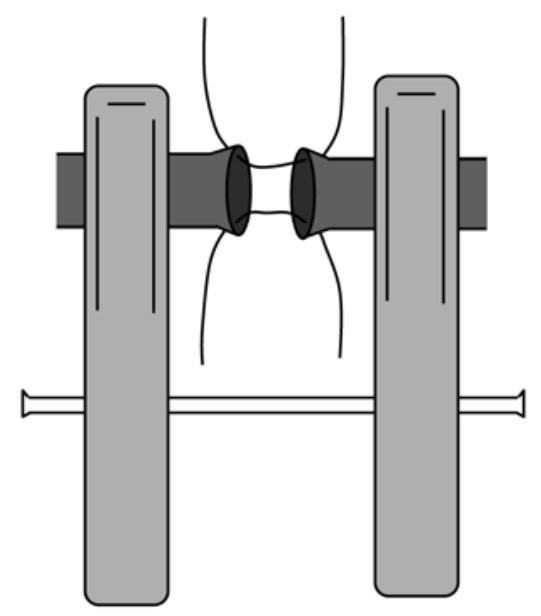

D

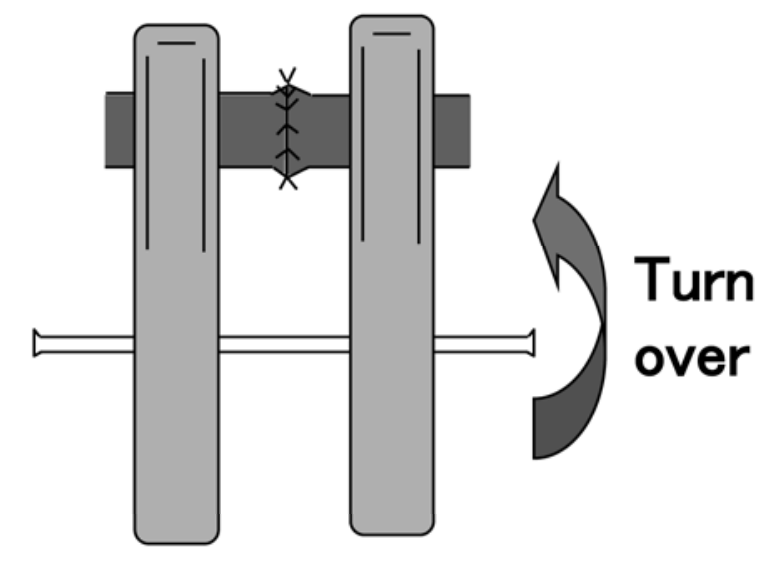

B

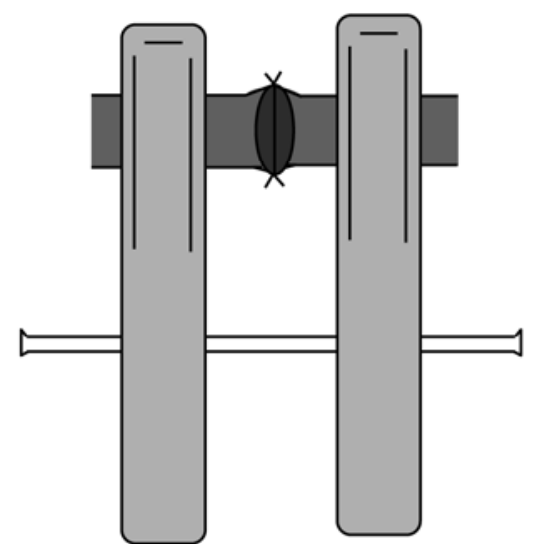

E

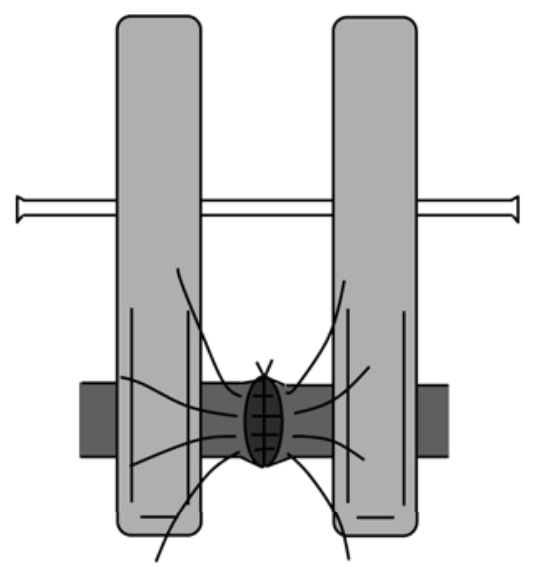

C

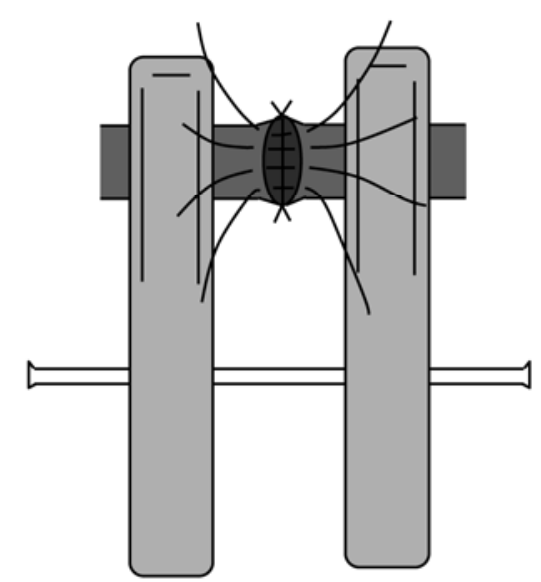

F

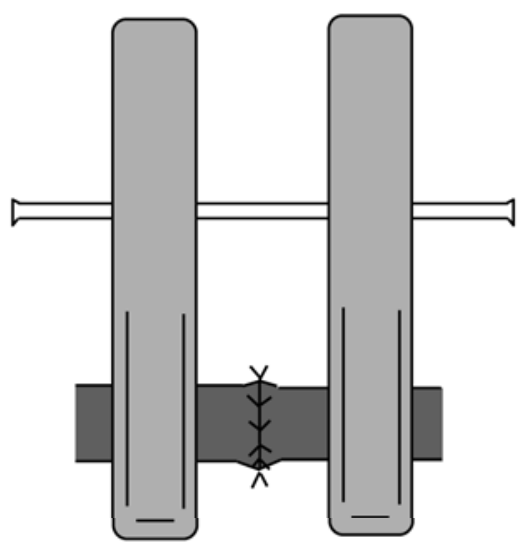


Figure 2

A

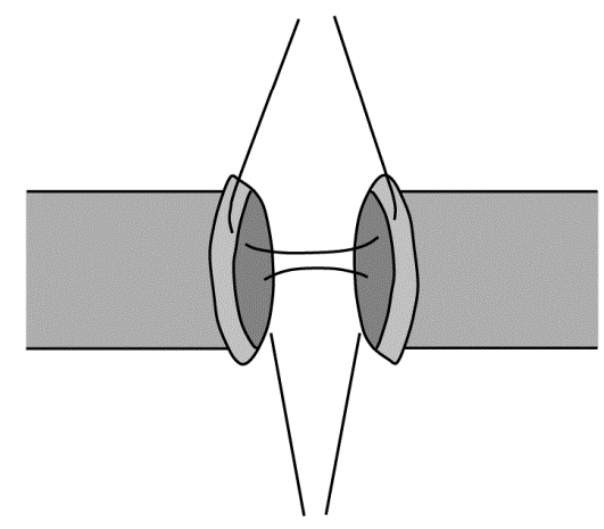

D

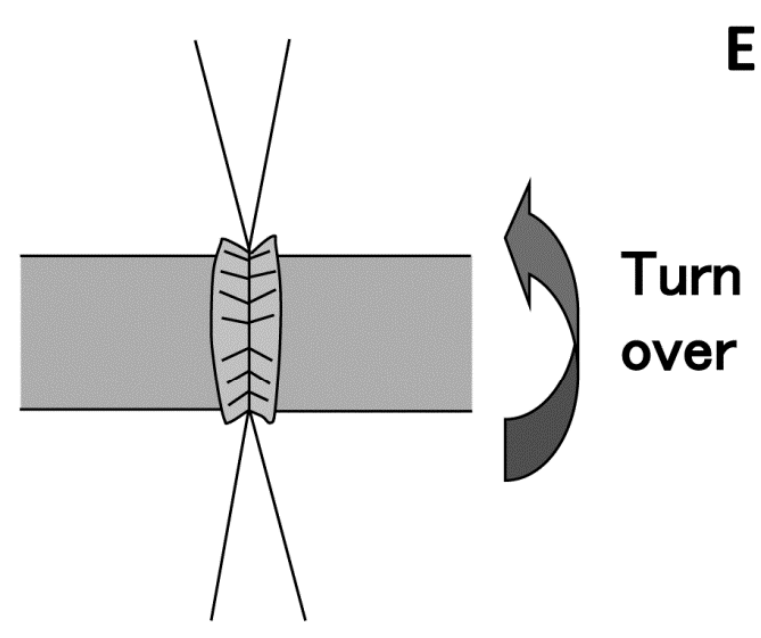

B

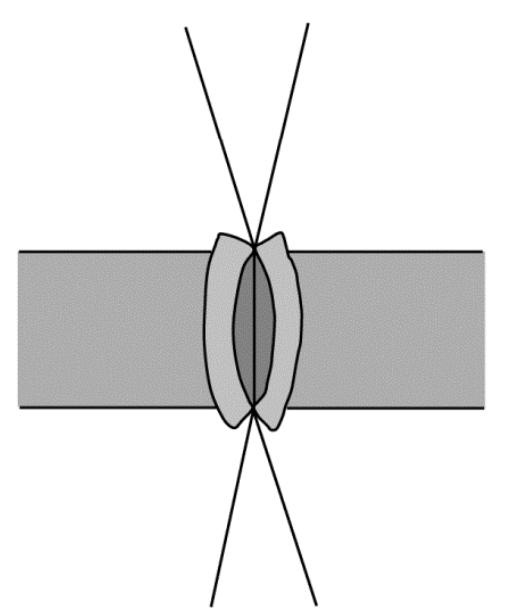

E

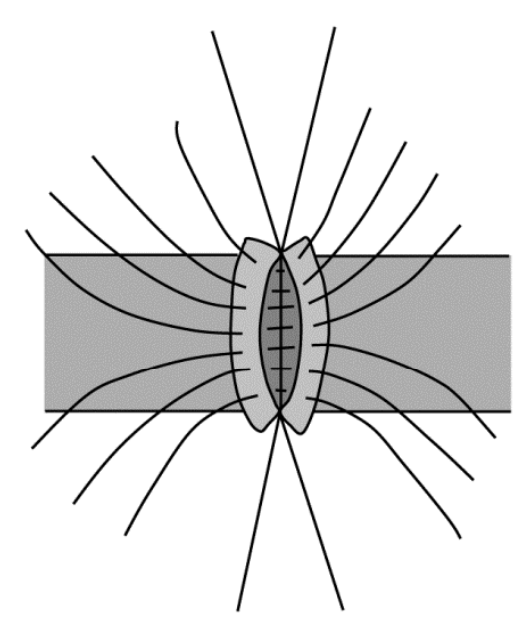

C

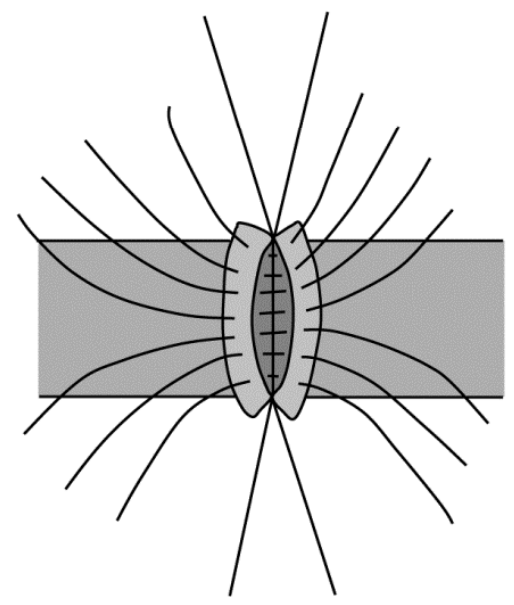

F

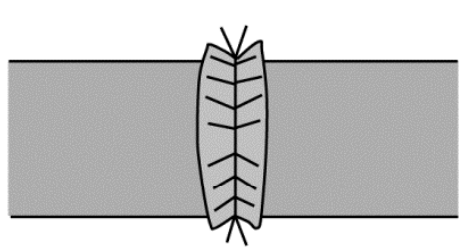


Figure 3
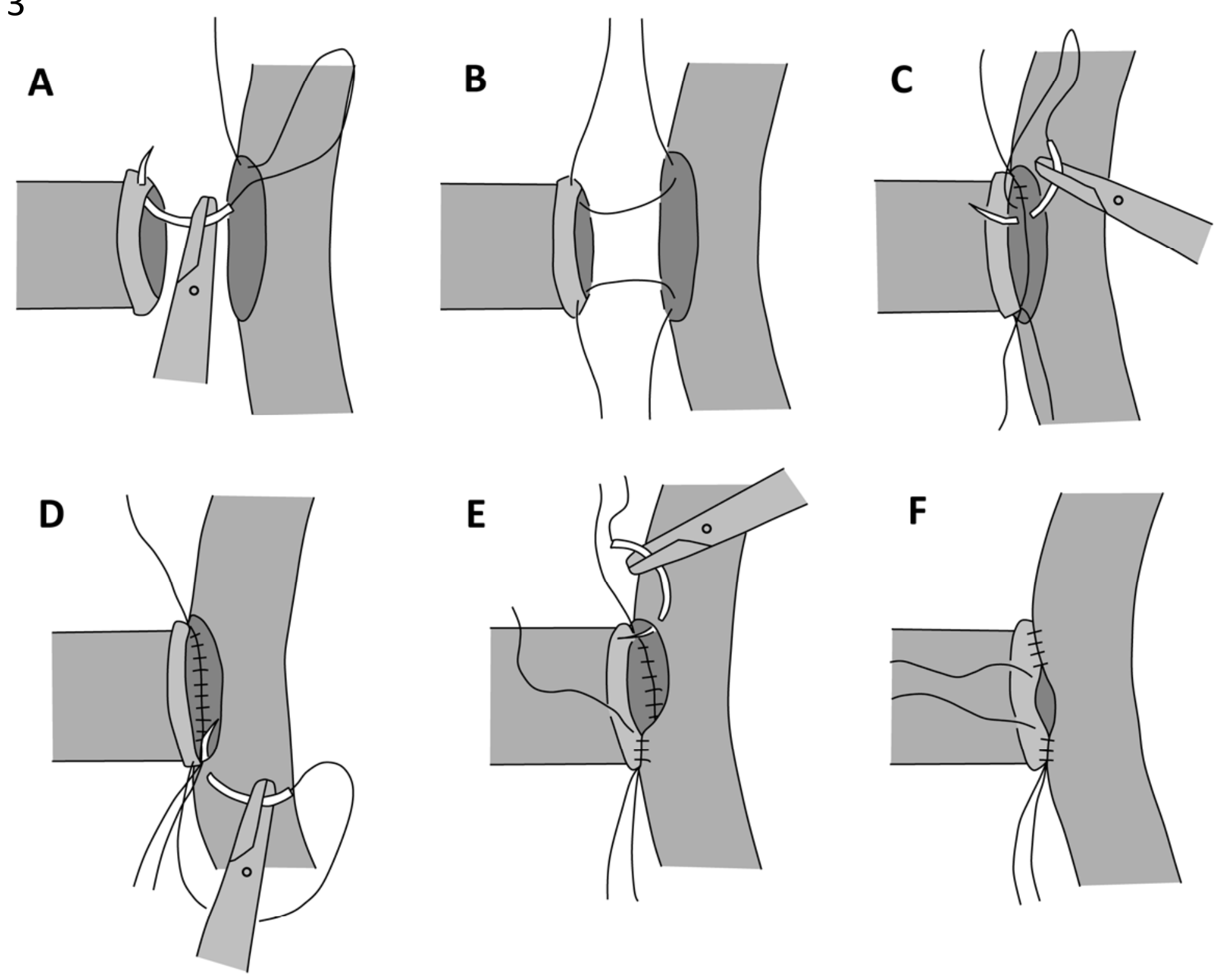
Figure 4

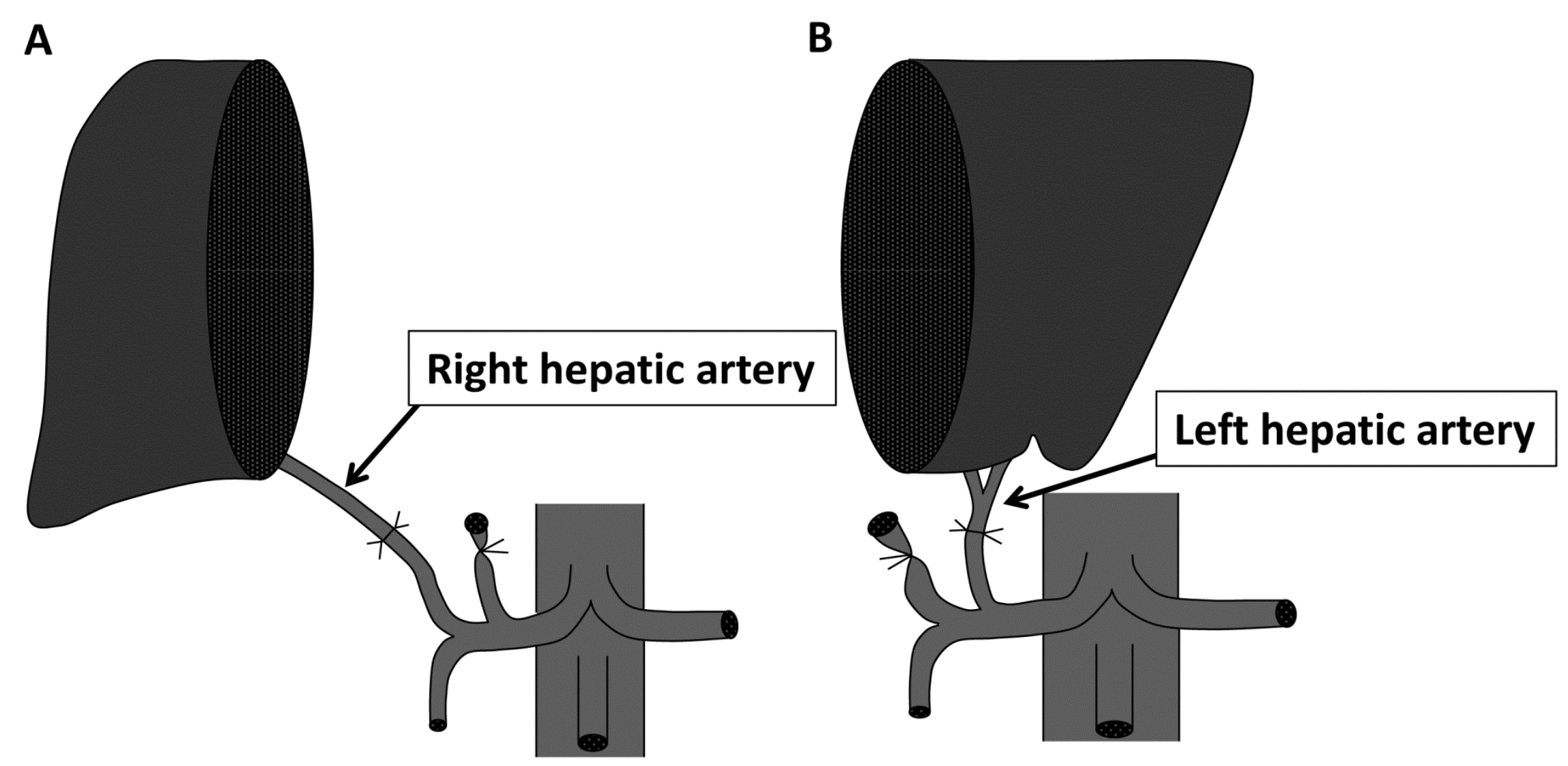


Figure 5

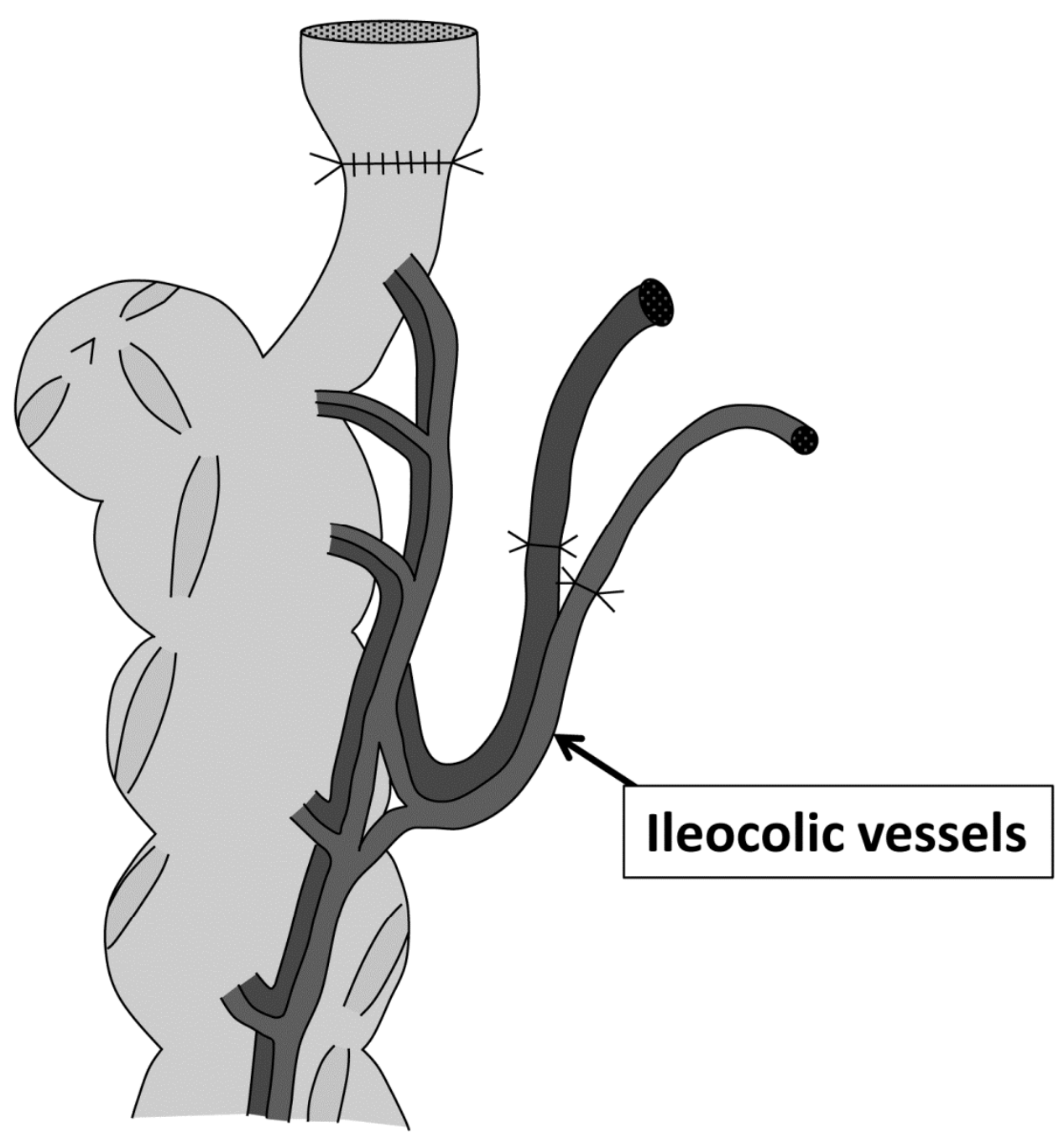


Figure 6

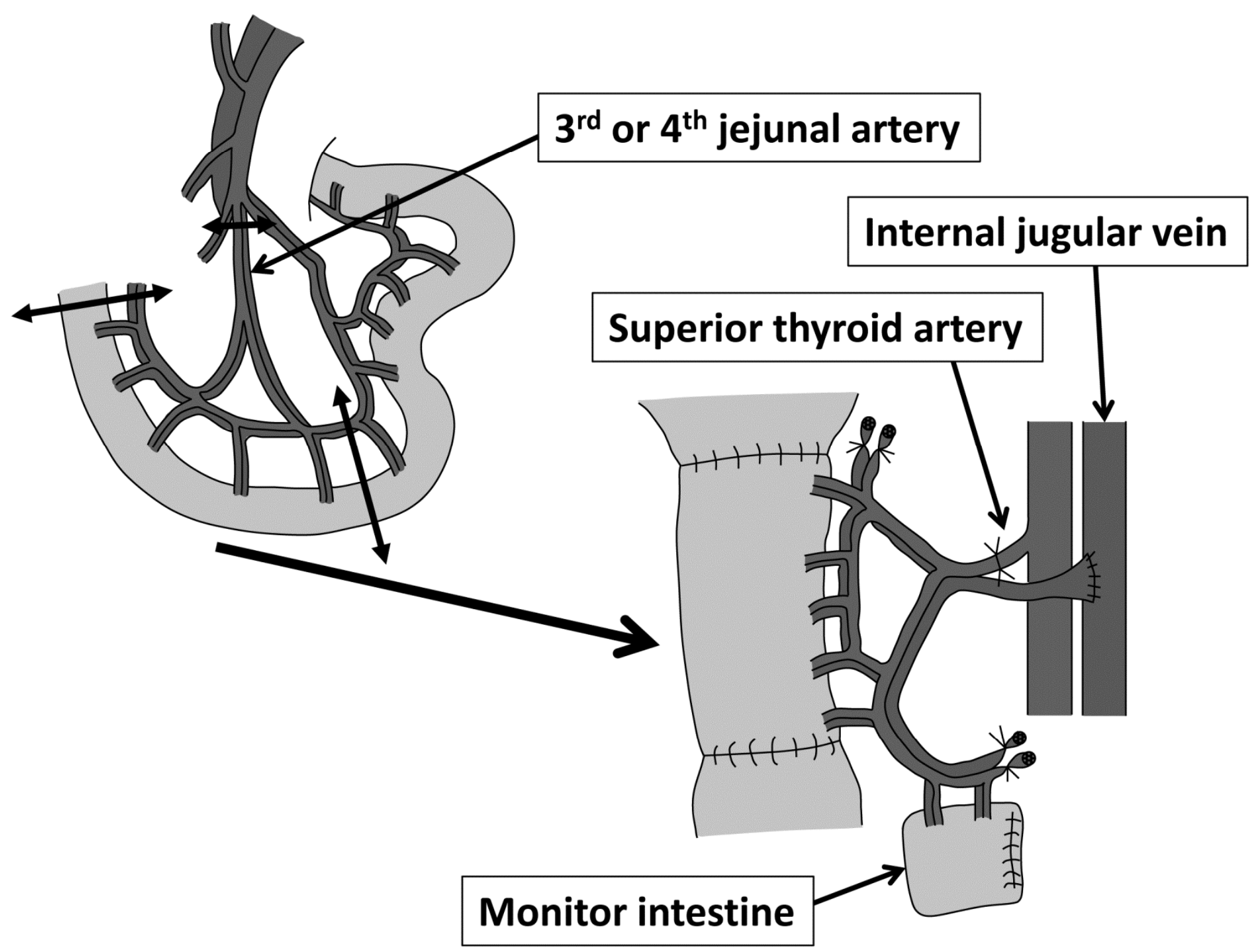


Figure 7
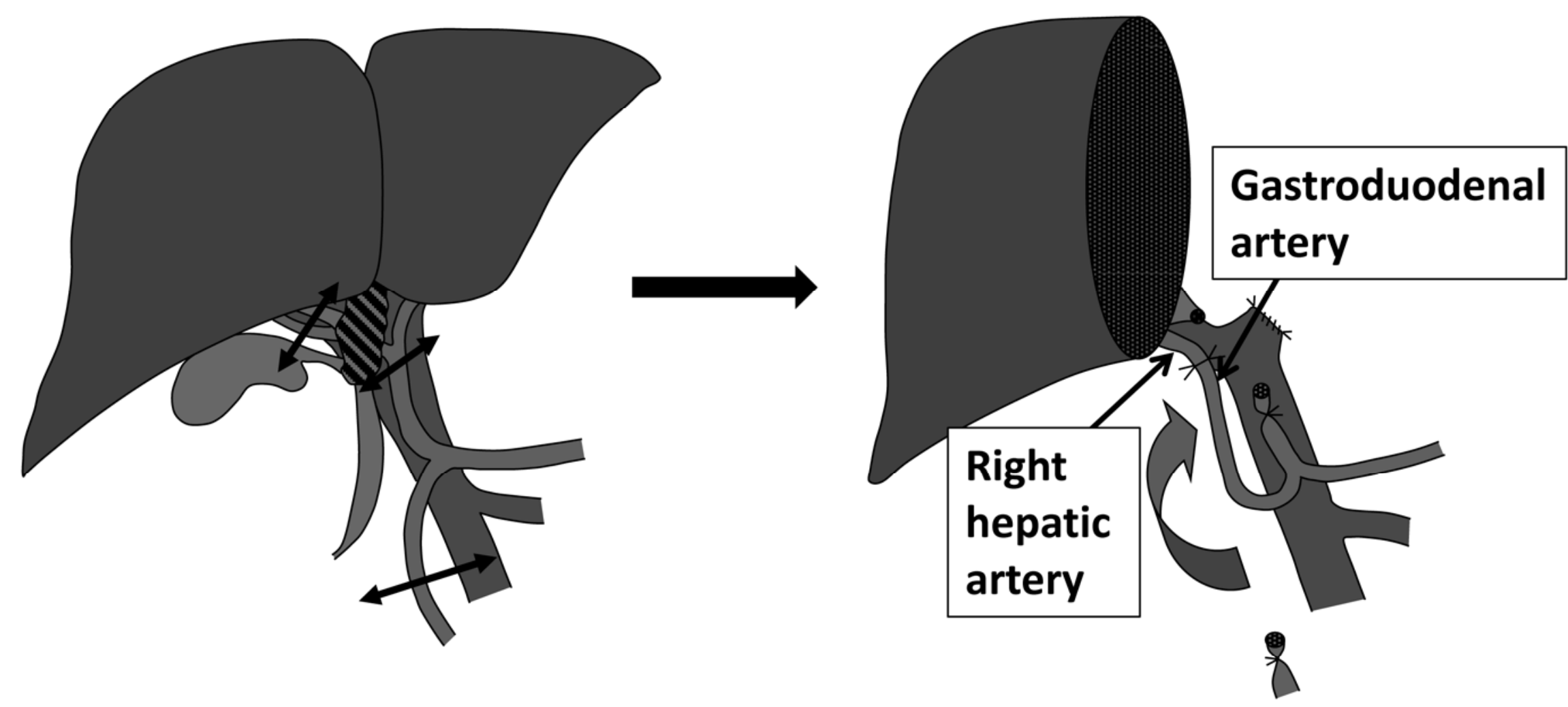
Figure 8

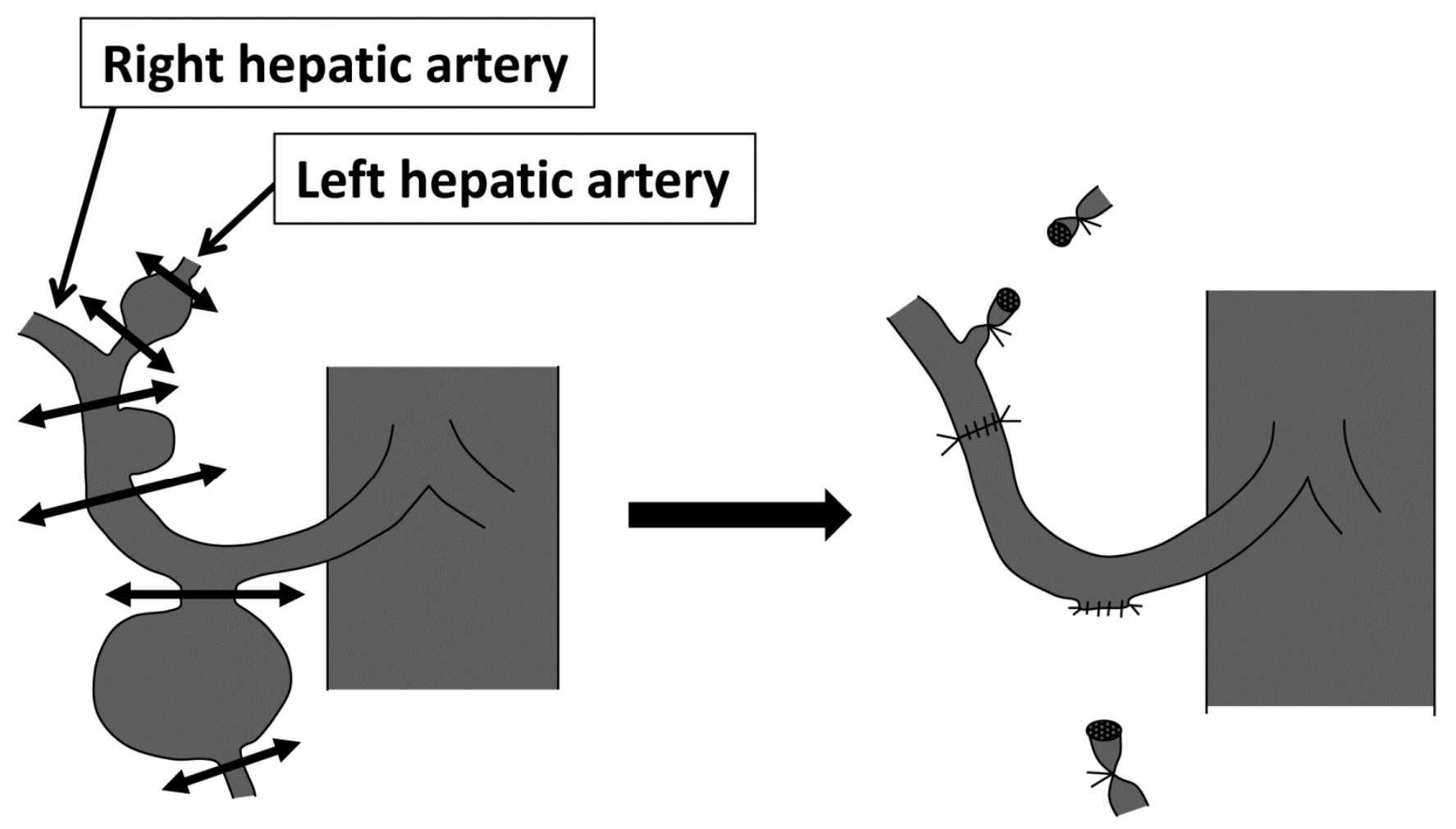


Figure 9

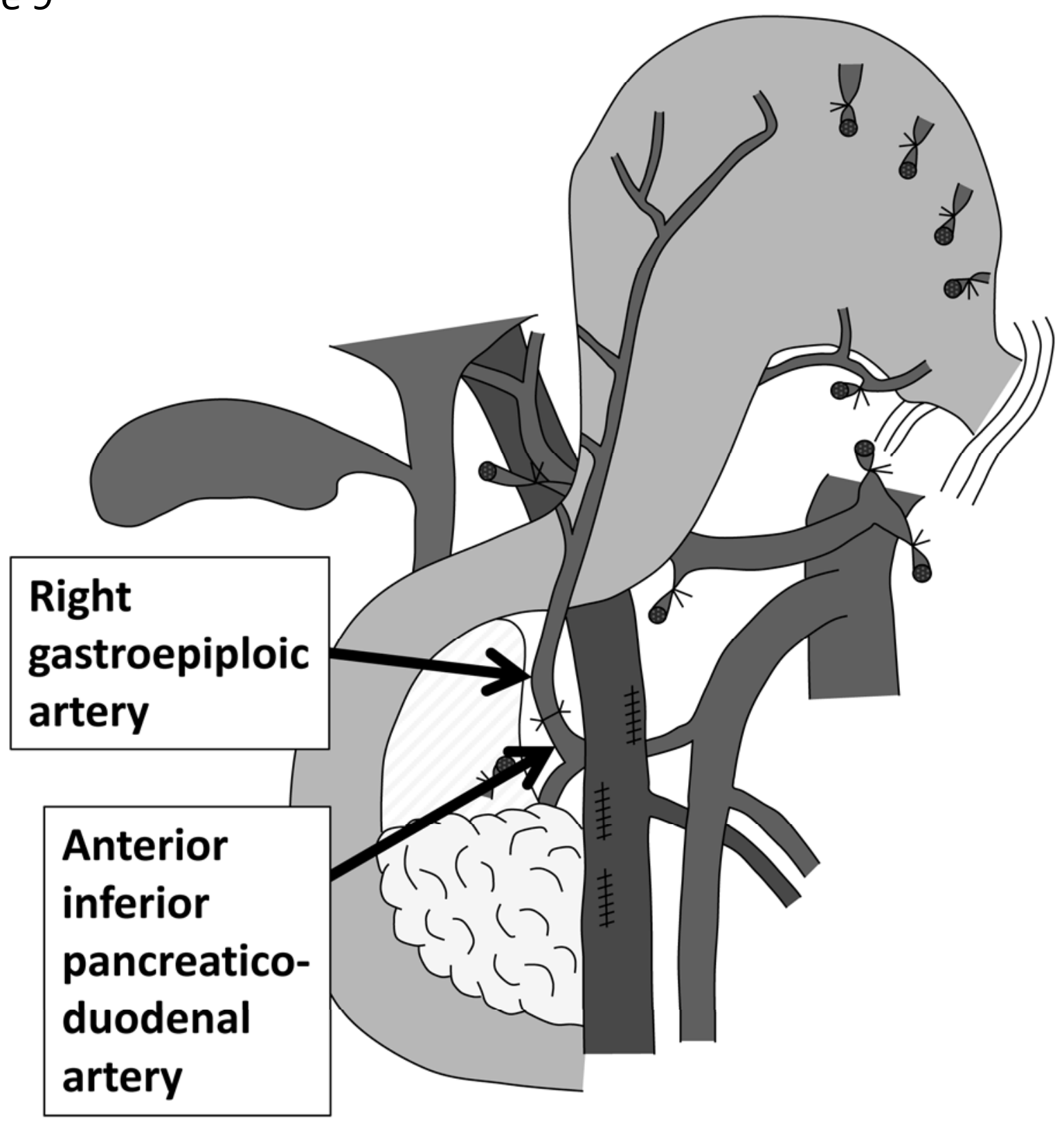


Figure 10

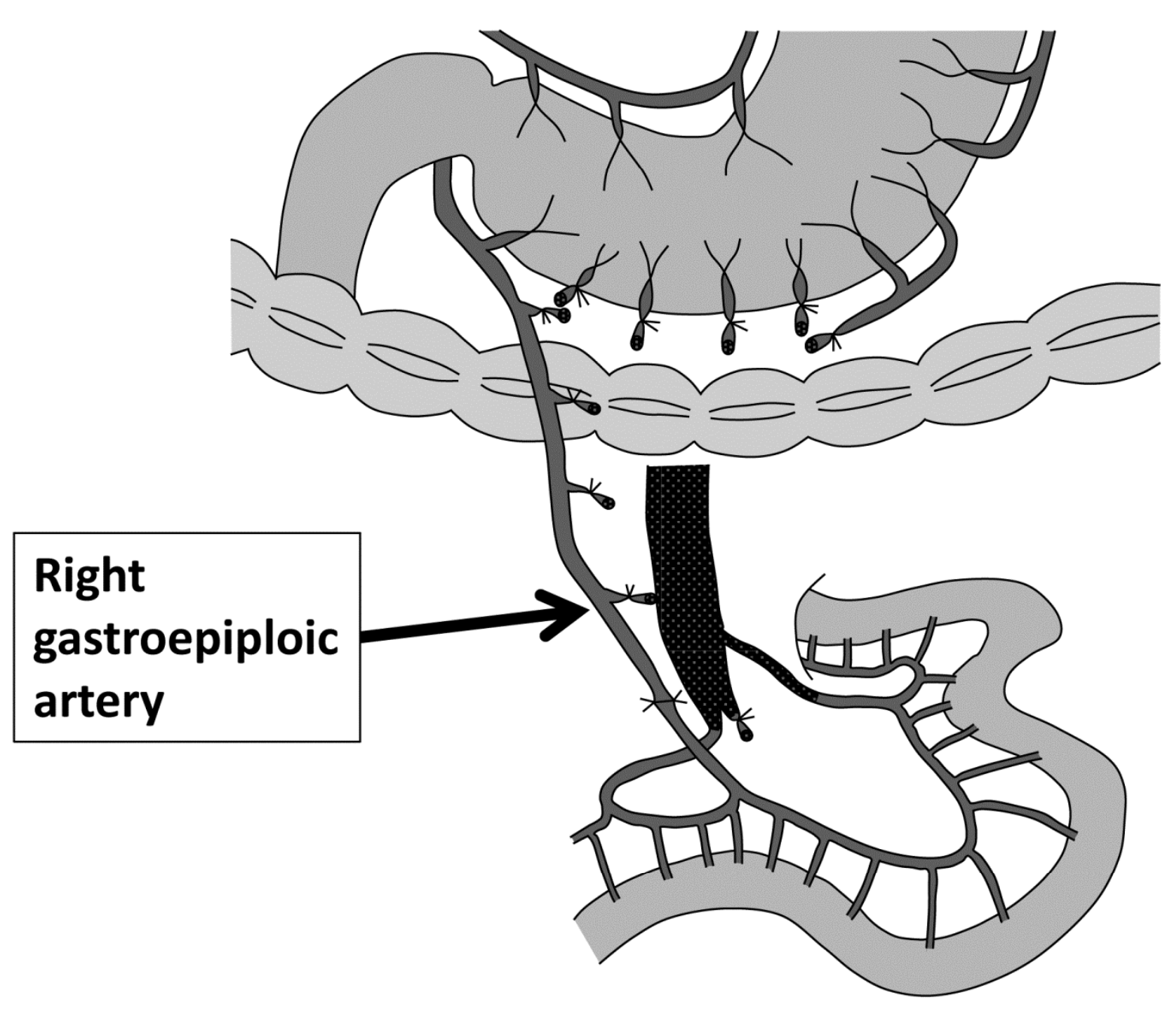

